University of South Carolina

Scholar Commons

$5-1-2005$

\title{
Effects of Density on Timing of Emergence and its Consequences for Survival and Growth in Two Communities of Annual Plants
}

\author{
Roy Turkington \\ University of British Columbia, royt@interchange.ubc.ca \\ Deborah E. Goldberg \\ University of Michigan - Ann Arbor, degold@umich.edu \\ Linda Olsvig-Whittaker \\ Blaustein Institute of Desert Research, linda.whittaker@nature-parks.org.il \\ Andrew R. Dyer \\ University of South Carolina - Aiken, AndyD@usca.edu
}

Follow this and additional works at: https://scholarcommons.sc.edu/aiken_biology_geology_facpub

Part of the Biology Commons, and the Weed Science Commons

\section{Publication Info}

Published in Journal of Arid Environments, Volume 61, Issue 3, 2005, pages 377-396.

(C) 2004 Elsevier Ltd. All rights reserved. Licensed with a CC-BY-NC-ND license.

Turkington, R., Goldberg, D. E., Olsvig-Whittaker, L., \& Dyer, A. R. (2005). Effects of density on timing of emergence and its consequences for survival and growth in two communities of annual plants. Journal of Arid Environments, 61(3), 377-396. https://doi.org/10.1016/j.jaridenv.2004.09.016 inclusion in Faculty Publications by an authorized administrator of Scholar Commons. For more information, please contact digres@mailbox.sc.edu. 
Journal of

Arid

ELSEVIER

\title{
Effects of density on timing of emergence and its consequences for survival and growth in two communities of annual plants
}

\author{
R. Turkington ${ }^{\mathrm{a}, *}$, D.E. Goldberg ${ }^{\mathrm{b}, \mathrm{c}}$, L. Olsvig-Whittaker ${ }^{\mathrm{c}, 1}$, \\ A.R. Dyer ${ }^{b, 2}$ \\ ${ }^{a}$ Department of Botany, University of British Columbia, Vancouver, BC, Canada V6T $1 Z 4$ \\ ${ }^{\mathrm{b}}$ Department of Ecology and Evolutionary Biology, University of Michigan, Ann Arbor, MI 48109, USA \\ ${ }^{\mathrm{c}}$ Mitrani Department for Desert Ecology, Blaustein Institute of Desert Research, Ben Gurion Campus 84990 , \\ Israel
}

Received 24 October 2003; received in revised form 7 September 2004; accepted 14 September 2004 Available online 8 December 2004

\begin{abstract}
We tested whether increasing seed density results in a change in the timing of emergence in two communities of sand dune annual plants in Israel. Specifically we tested (i) if emergence is accelerated or delayed due to high seed density. We also tested two predictions about the consequences of changes in the timing of emergence; (ii) seedlings emerging earlier will have higher survival and growth; (iii) the advantage of earlier emergence increases as seed density increases. We examined these predictions for both monocots and dicots growing under different irrigation regimes and using species from a desert and a semi-arid community of sand dune annual plants. Dicots showed increasing negative density-dependent emergence in later cohorts, consistent with the prediction of delayed emergence. In contrast, grasses showed no shift in timing of emergence, although they did experience strongly negative densitydependence in the large intermediate cohort, with the first and the last-emerging cohort

\footnotetext{
${ }^{*}$ Corresponding author. Tel.: + 16048222141 ; fax: +16048226089 .

E-mail addresses: royt@interchange.ubc.ca (R. Turkington), degold@umich.edu (D.E. Goldberg), linda.whittaker@nature-parks.org.il (L. Olsvig-Whittaker), andyd@usca.edu (A.R. Dyer).

${ }^{1}$ Current address: Science Division, Israel Nature and National Parks Protection Authority, $3 \mathrm{Am}$ Veolami Street, Jerusalem 9546, Israel.

${ }^{2}$ Current address: Department of Biology and Geology, University of South Carolina Aiken, Aiken, SC
} 29801, USA.
\end{abstract}

0140-1963/\$ - see front matter (C) 2004 Elsevier Ltd. All rights reserved. doi:10.1016/j.jaridenv.2004.09.016 
showing weaker and less significant negative density-dependence. Cohort had no impact on survival with earlier emerging seedlings being no more or less likely to survive to the end of the growing season than later emerging seedlings. For dicots, earlier emerging seedlings tended to become larger adults, especially for plants from the desert site. Our results differ from those of other field studies where timing of emergence seems to have a larger effect on components of fitness. We suggest that most other field studies have been conducted in more productive habitats where asymmetric competition through light limitation is much more likely and therefore small differences in timing are expected to have larger cumulative effects.

(C) 2004 Elsevier Ltd. All rights reserved.

Keywords: Competition; Demography; Density-dependence; Desert; Population regulation

\section{Introduction}

Demographic studies of plant populations have demonstrated that many more seeds germinate than are able to survive to become adults. Many different factors may determine which seedlings survive and reproduce. Variation in the timing of seedling emergence is one such well-studied factor (Salisbury, 1963; Howell, 1981; Kalisz, 1986; Miller, 1987; van der Toorn and Pons, 1988; Biere, 1991; Rees, 1994; Murray, 1998). This is a plant life history trait that is expected to influence subsequent probability of survival, and reproductive output (Weiner, 1985; Rice, 1987; Clauss and Venable, 2000; Smith et al., 2000). In addition, timing of emergence has a profound effect on the outcome of competition both within and between species (see Refs. in Biere, 1991; Rees, 1997a, pp. 214-238; 1997b, pp. 121-142; Hutchings, 1997, pp. 325-358; Rice and Dyer, 2001), with earlier-emerging plants typically dominating resources, and suppressing the growth of later-emerging individuals (e.g., Ross and Harper, 1972; Fowler, 1984). Many studies have shown an apparent trade-off between survival and reproduction, such that earliergerminating seeds typically have lower survival but higher reproduction (Table 12.2 in Baskin and Baskin, 1998). However, some studies (e.g., Kalisz, 1986) have shown both higher survival of plants from earlier-germinating seeds and higher fecundity. Because timing of emergence influences survival, growth, competitive ability and ultimately plant fitness, it is expected to be a crucial trait in the shaping of plant life histories, especially in annual plants, where such effects are likely to persist for a greater proportion of the life cycle than in longer-lived plants.

Variation in the timing of seedling emergence may be due to genetic factors (Rees, 1994), or to environmental factors such as small-scale differences in topography (Harper et al., 1965), resource level (Clauss and Venable, 2000), or seed density (Ellner, 1986). While seed density is known to have strong effects on overall emergence (both inhibitory (Goldberg et al., 2001) and facilitative (Dyer et al., 2000; Bergelson and Perry, 1989), the effects of density on the timing of emergence and subsequent consequences of this timing for growth or survival have rarely been combined in experimental studies (but see Bergelson and Perry, 1989). Density effects on germination timing in annuals are particularly interesting because at least 
three mechanisms have been discussed in the literature, with some evidence for each of them, albeit from only a few tested species in each case. These three mechanisms of density-dependent ${ }^{3}$ timing of germination have quite different consequences for net fitness; the first two are adaptive responses by the target plants to avoid competition, and the third is not under the control of the plant. First, seeds at high density could germinate earlier in the season, i.e. "adaptive acceleration", and so avoid the competitive disadvantage occurring for later emergents at high density (see Dyer et al., 2000 and references therein). Second, seeds could respond to high seed density by delaying germination to a subsequent year, i.e. "adaptive delay", when they may have a more favorable environment. This reduces competitive loss of seedlings but, even for seeds with dormancy, this should result in an increased chance of seed mortality before the next season, some loss of seed vigor, and a fitness cost due to delayed reproduction even if the seeds survive and germinate in some subsequent year (Bulmer, 1984; Rees, 1997a,b). A third possibility is that germination may simply be competitively inhibited (Bergelson and Perry, 1989) within that season and this subjects seedlings to the costs associated with delayed emergence mentioned above or complete mortality if dormancy is absent or limited.

Regardless of the causes of variation in timing of emergence, early emergence is likely to be advantageous at least for growth and reproduction, and possibly for survival. Density should exacerbate the effects of this variation on fitness: i.e. any competitive advantage of earlier emergence for subsequent growth and survival should become stronger as density and overall competition intensity increases (Ross and Harper, 1972).

In a previous paper (Goldberg et al., 2001), we reported on average responses by individual plants to changes in sowing density and irrigation level in experiments with two sand dune annual plant communities in Israel. Strong evidence of community-level density-dependence was detected at all three life stages we studied: emergence, survival, and final size. Emergence and final size tended to be negatively density-dependent, while survival tended to be positively affected by, or neutral to, increasing density. It is unlikely that these effects were distributed evenly among plants germinating at different times and therefore conclusions drawn from plot totals may mask important interactions between timing of emergence and density.

In this paper, we first test alternative hypotheses about (i) the response of timing of emergence to density: The adaptive acceleration hypothesis predicts that the probability of emergence should increase with density for early cohorts but decrease with density for later cohorts. Alternatively, the adaptive delay (to a subsequent year) and competitive inhibition hypothesis both predict negative density-dependence for all cohorts, with the magnitude of this negative effect strengthening from early to late cohorts. Distinguishing between the latter two hypotheses requires data from subsequent years, which are not available for this system. Second, we test two

\footnotetext{
${ }^{3}$ The terminology of density-dependence has often been confused in the literature. Throughout this paper we use positive density-dependence or facilitation for positive effects of increasing density and negative density-dependence or competition for negative effects of increasing density. Increasing negative density dependence in later cohorts is a way of quantifying the delay in emergence.
} 
predictions about the consequences of the timing of emergence that are independent of any density-dependent shifts in timing. (ii) Seedlings emerging earlier will have higher survival and growth regardless of seed density. (iii) The advantage of earlier emergence increases as seed density increases (i.e. later germinants experience greater negative density-dependent effects on growth and survival).

We examined the degree to which these predictions were contingent on physical environment and plant type by testing them for dicots and graminoids under different irrigation regimes.

\section{Methods}

\subsection{Experimental system}

The experimental system and general methodology has been described in detail by Goldberg et al. (2001). The system consisted of annual plant communities occurring at two semi-stabilized sand dune sites in Israel — one desert and one semi-arid source community. Mean annual precipitation (MAP) (1951-1980 averages) is $110 \mathrm{~mm}$ at the desert site (Holot Mashabim, $31^{\circ} 00^{\prime} \mathrm{N} 34^{\circ} 44^{\prime} \mathrm{E}$ ), and $190 \mathrm{~mm}$ at the semi-arid site (Kerem Shalom, $31^{\circ} 12^{\prime} \mathrm{N} 34^{\circ} 18^{\prime} \mathrm{E}$ ) and typically falls between mid-November and mid-April. Each site is dominated by species-rich annual vegetation interspersed with scattered shrubs.

\subsection{Basic experimental approach}

We used the community-density design (Goldberg et al., 1995, 2001; Goldberg and Estabrook, 1998), which requires manipulation of the initial density of the entire community. Seed banks were collected from the two source sites and transplanted to a common experimental garden. Densities and productivity (through irrigation) of these transplanted communities were manipulated in a factorial experiment.

\subsection{Experimental garden}

The experimental "sandbox" garden was constructed at the Blaustein Institute for Desert Research at Sede Boqer, in the northern Negev Desert $\left(30^{\circ} 48^{\prime} \mathrm{N} 34^{\circ} 48^{\prime} \mathrm{E}\right.$; MAP $\left.98 \mathrm{~mm}\right)$. The garden consists of 448 plots, arranged in 28 "trenches" of eight large $(1 \mathrm{~m} \times 1 \mathrm{~m})$ and eight small $(0.50 \mathrm{~m} \times 0.50 \mathrm{~m})$ plots each. Each $2 \mathrm{~m} \times 10 \mathrm{~m}$ trench was dug to $1 \mathrm{~m}$ depth and then corrugated plastic liners were placed in the excavated area to separate the 16 plots in each trench from each other and from the surrounding loess soil. The plots were then filled with sterile sand collected at depth from the same dune system as the desert source site. 


\subsection{Seed bank collection, preparation and sowing}

At each of the two source sites, surface sand $(0-2 \mathrm{~cm}$ depth) was collected in September 1992. Samples from within each source site were combined. A fine sieve (350 $\mu \mathrm{m}$ mesh size) successfully separated the seedbank from the sand substrate and all material that did not pass through the sieve was used as the seedbank.

On January 14, 15, 1993, an initial community density (ICD) gradient was established by sowing different amounts of this concentrated seed bank onto the surface of standard size plots. A geometric series of eight densities was used: $\frac{1}{16}, \frac{1}{8}, \frac{1}{4}, \frac{1}{2}$, $1,2,4$ and $8 \times$ the average density (assessed as mass) of seedbank in the field. These highest seed bank densities $(2 \times, 4 \times$ and $8 \times)$ were planted into the $0.25 \mathrm{~m}^{2}$ plots; all other ICDs were planted in the $1 \mathrm{~m}^{2}$ plots. The seed bank was spread uniformly across the surface of the sand of each plot, covered by $1 \mathrm{~cm}$ of sterile sand and lightly watered to prevent loss of seed bank by blowing wind.

\subsection{Irrigation treatments}

Three irrigation treatments were used to mimic the precipitation regimes of the two source sites, plus a wetter coastal site (Caesarea, $32^{\circ} 30^{\prime} \mathrm{N} 34^{\circ} 55^{\prime} \mathrm{E}$; MAP $550 \mathrm{~mm}$ ). Water was applied as a fine spray from a hand-held hose for each plot keeping track of amounts applied to each plot by a flow meter. Long-term rainfall records indicate that, on average, the desert and coastal sites receive, respectively, 1.1 and 5.8 times the annual precipitation of the garden site at Sede Boqer. After each naturally occurring rainfall event at Sede Boqer, water was supplied to each irrigation treatment to maintain these proportional differences, with the intermediate treatment receiving the midpoint of these extremes (3.45 times precipitation at Sede Boqer). Further details are provided in Goldberg et al. (2001).

\subsection{Experimental design}

We used a factorial design of two source communities (desert and semi-arid) $\times 3$ irrigation treatments $\times 8$ ICD values, each replicated two or four times (densities of $\frac{1}{16} \times, \frac{1}{18} \times$, had four replicates in $1 \mathrm{~m}^{2}$ plots; $\frac{1}{4} \times, \frac{1}{2} \times, 1 \times$ densities had two replicates in $1 \mathrm{~m}^{2}$ plots, and because of limitation of seed banks, $2 \times, 4 \times, 8 \times$ had two replicates in $0.25 \mathrm{~m}^{2}$ plots). The semi-arid site had half as many replicates of each density in the intermediate irrigation treatment giving a total of 110 experimental plots $\left(771 \mathrm{~m}^{2}\right.$ and $330.25 \mathrm{~m}^{2}$ ). Each trench also had two "control" plots (one large and one small) with no seed bank added to test for immigration of seeds from outside the experimental plots.

\subsection{Monitoring and harvest}

Each plot had a $10 \mathrm{~cm}$ buffer zone in which we sowed a seedbank but did not monitor or harvest plants. Therefore, effective plot sizes were $80 \mathrm{~cm} \times 80 \mathrm{~cm}$ and $30 \mathrm{~cm} \times 30 \mathrm{~cm}$ for large and small plots, respectively. We monitored all plots at 10-19 
day intervals over the season to assess timing of emergence and the consequences of timing for subsequent fate. At each census, we marked all new individuals with color-coded (by cohort) toothpicks. The number of surviving plants from previous censuses was recorded for each cohort. Toothpicks next to dead or missing plants were removed and counted to determine mortality rates of each cohort. The first census was taken on February 11, 1993 and the final (fifth) census and destructive harvest of above-ground biomass on 19-22 April, after cessation of natural rainfall and as most species were just beginning to senesce. We harvested plants by cohort in subplots that had individually marked plants, and as a group in the remaining subplots. All harvested material was placed in a freezer; the low water-content of the plants kept them in excellent condition until they were unfrozen, sorted to species, counted, dried and weighed.

\subsection{Statistical analyses}

All analyses were conducted with SYSTAT v. 7.0 for WINDOWS (SPSS, 1997). For each of the dependent variables described below, we used a repeated measures ANCOVA to test effects of time of emergence (cohort), a measure of density as a covariate, and source community (desert or semi-arid), growth form (dicot or graminoid), and irrigation (low, intermediate, high) as categorical factors. The means of the response variable for each cohort were treated as the repeated measures. Because the first two cohorts were usually considerably larger than the three later cohorts, we grouped the last three cohorts and treated them as a single cohort in this and all other analyses; results were qualitatively identical if all cohorts were kept separate. Effects of timing (cohort) on the magnitude of density dependence are tested by the interaction between time (cohort) and density.

For analyses of individual performance, the biological null hypotheses are that per-seedling probability of emergence, survival probability, and mass per plant are all independent of density, i.e. have slopes of 0 when regressed against the appropriate measure of density (see below). Significant negative slopes indicate negative density dependence (competition). More details are provided in Goldberg et al. (2001).

The appropriate density measure to use as a covariate to assess density effects depended on the life stage. For probability of emergence, the appropriate density measure was the sowing density, expressed as a fraction of natural seed bank (from $\frac{1}{16}$ of natural to 8 times natural). For survival, the appropriate density measure was density of emerging seedlings. This was expressed as the cumulative emergence over the entire season. For final mass, the appropriate density measure was final density of surviving plants at the end of the season; this excluded plants that died before or during the peak period of growth during the relatively warm months of March and early April. In all cases, the density measure was the total density of dicots and graminoids combined.

To quantify the timing of emergence to test prediction $i$, we used an index of the probability that an individual seedling would emerge as the response variable. This probability of emergence was calculated separately for dicots and graminoids in each 
plot as the absolute number of emergents per cohort divided by the relative seedbank density, where relative seed bank density varied from $\frac{1}{16} \times$ to $8 \times$ natural density. Differences in the magnitude of density-dependent emergence between cohorts would be reflected by significant time (i.e., cohort) $\times$ density interactions in repeated measures ANCOVAs with relative seedbank density as the covariate. Adaptive delay or competitive inhibition of emergence would be reflected by increasingly negative density dependence for later cohorts.

To test the second and third predictions about the consequences of timing of emergence and its interaction with density, we conducted similar repeated measures ANCOVAs for probability of survival of each cohort and mean mass per plant of each cohort. Survival was calculated as the number of seedlings in a cohort surviving to the end of the growing season/number of emerged seedlings in that cohort. Final size was calculated as the total biomass of plants in a cohort at harvest/number of surviving plants in the cohort. Both survival and size/plant were calculated separately for dicots and grasses for each cohort in each plot.

Before analysis, data were transformed to linearize the performance-density relationships so that slopes could be compared between the experimental factors with ANCOVA. For growth, ln-ln transformation provided the best fit to a linear model. For emergence probability and survival, a ln transformation of only the density variable provided the best fit.

\section{Results}

\subsection{Probability of emergence}

The largest cohort for both growth forms ( $>40 \%$ ) was always the second cohort that emerged between 4 and $5 \frac{1}{2}$ weeks after sowing (Fig. 1). Overall, the probability of emergence differed highly significantly $(P<0.001)$ among cohorts (Table 1$)$. Dicots tended to emerge later than grasses (Fig. 1; significant $(P<0.001)$ cohort $\times$ form interaction in Table 1). Probability of emergence also tended to be higher for later cohorts in the semi-arid than in the desert source community (Fig. 1; significant $(P<0.001)$ cohort $\times$ source community interaction in Table 1$)$, despite both source communities receiving exactly the same irrigation regimes. Emergence phenology was also somewhat influenced by irrigation according to the significant $(P=0.006)$ cohort $\times$ irrigation interaction (Table 1$)$, but no clear pattern is obvious from Fig. 1.

Density-dependence differed among cohorts (significant $(P<0.001)$ cohort $\times$ density interaction in Table 1; Figs. 2 and 3) and, when it occurred, was always negative. That is, increasing density either decreased the probability of an individual seedling emerging or had no effect. For dicots, the earliest cohort never showed significant density dependence, the intermediate cohort exhibited significant $(P<0.05)$ density dependence in two of the six cases, and the latest cohort exhibited significant $(P<0.05)$ density-dependence in five of the six cases, with slopes similar to those for the intermediate cohort (Figs. 2 and 3), consistent with our predictions for either 


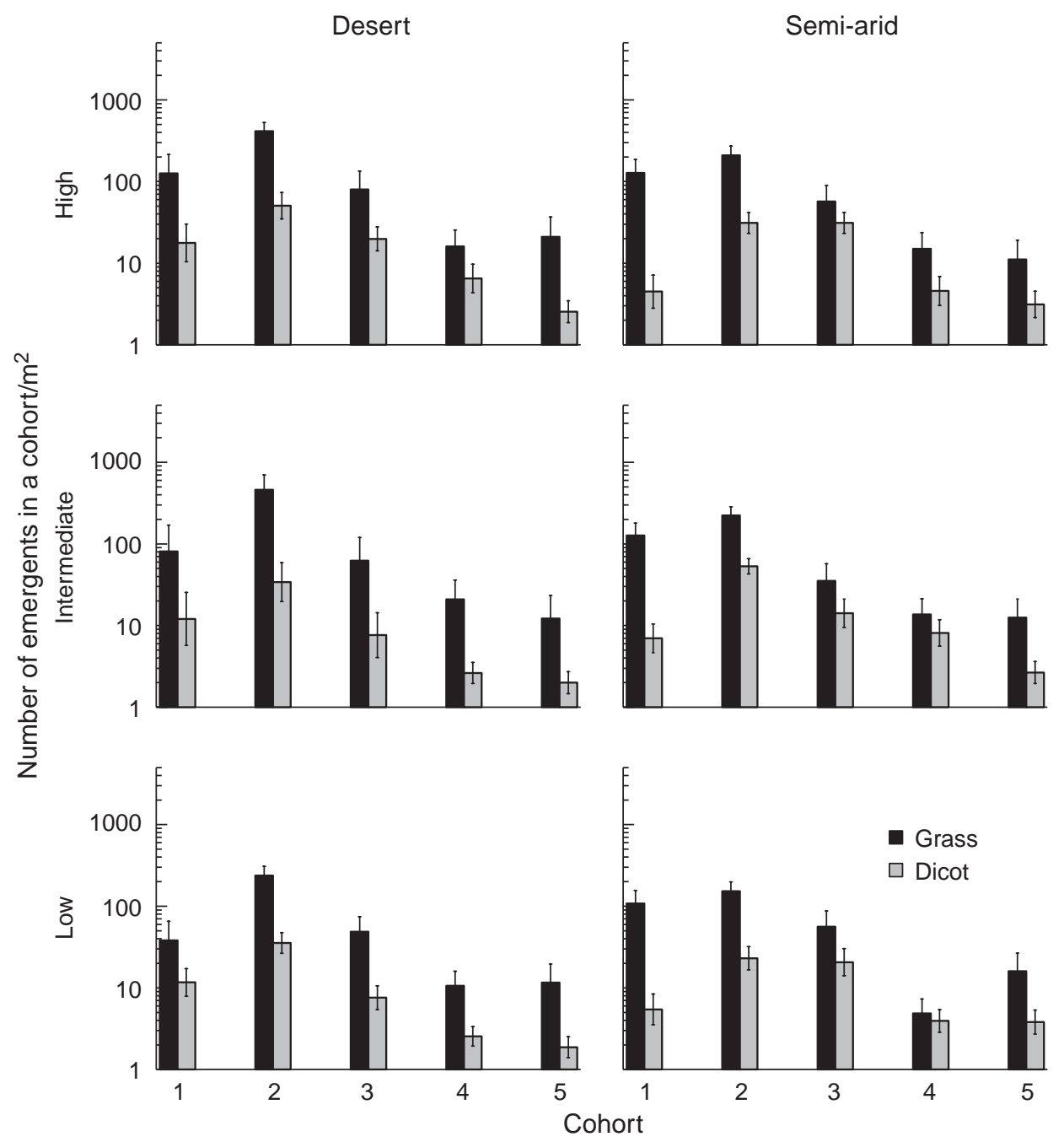

Fig. 1. Timing of emergence of cohorts from desert and semi-arid source communities grown under three irrigation regimes. Bars are mean $( \pm 1 \mathrm{SE})$ number of grass or dicot seedlings emerging per $\mathrm{m}^{2}$ that belong to a particular cohort.

adaptive delay or competitive inhibition. However, the earliest and the latest cohorts of grasses never showed significant density-dependence of emergence, while the intermediate cohort always showed significant $(P<0.05)$ negative density dependence (Figs. 2 and 3). These differences between growth forms in timing and magnitude of density-dependence are reflected in the significant $(P<0.001)$ cohort $\times$ form $\times$ density interaction in Table 1 . While the interaction of density and cohort with source community was also highly significant $(P=0.001$, Table 1$)$, 
Table 1

$P$-values from repeated-measures multivariate ANCOVAs for values from each cohort of probability of emergence, probability of survival, and mass per plant

\begin{tabular}{|c|c|c|c|c|c|c|}
\hline & \multicolumn{2}{|c|}{$\begin{array}{l}\text { Probability of } \\
\text { emergence Figs. 1-3 }\end{array}$} & \multicolumn{2}{|c|}{$\begin{array}{l}\text { Probability of } \\
\text { survival Figs. 4-6 }\end{array}$} & \multicolumn{2}{|c|}{ Mass/plant Fig. 7} \\
\hline & df & $P$ & $\mathrm{df}$ & $P$ & df & $P$ \\
\hline Cohort & 2193 & $<0.001$ & 2152 & 0.434 & 2137 & 0.931 \\
\hline \multicolumn{7}{|l|}{ Cohort $x$} \\
\hline Source community & 2193 & $<0.001$ & 2152 & 0.189 & 2137 & 0.761 \\
\hline Form & 2193 & $<\mathbf{0 . 0 0 1}$ & 2152 & 0.158 & 2137 & 0.656 \\
\hline Irrigation & 4386 & 0.006 & 4304 & 0.007 & 4274 & 0.033 \\
\hline Density & 2193 & $<0.001$ & 2152 & 0.431 & 2137 & 0.487 \\
\hline Source $\times$ density & 2193 & 0.001 & 2152 & 0.153 & 2137 & 0.830 \\
\hline Form $\times$ density & 2193 & $<0.001$ & 2152 & 0.155 & 2137 & 0.772 \\
\hline Irrig $\times$ density & 4386 & 0.214 & 4304 & 0.004 & 4274 & 0.017 \\
\hline Source $\times$ form $\times$ density & 2193 & $<\mathbf{0 . 0 0 1}$ & 2152 & 0.177 & 2137 & 0.085 \\
\hline Source $\times$ irrig $\times$ density & 4386 & 0.136 & 4304 & 0.713 & 4274 & 0.667 \\
\hline Form $\times$ irrig $\times$ density & 4386 & 0.033 & 4304 & 0.020 & 4274 & 0.447 \\
\hline Source $\times$ form $\times$ irrig $\times$ density & 4386 & 0.662 & 4304 & 0.046 & 4274 & 0.983 \\
\hline Source $\times$ form & 2193 & $<0.001$ & 2152 & 0.175 & 2137 & 0.021 \\
\hline Source $\times$ irrig & 4386 & 0.715 & 4304 & 0.691 & 4274 & 0.566 \\
\hline Form $\times$ irrig & 4386 & 0.036 & 4304 & 0.019 & 4274 & 0.394 \\
\hline Source $\times$ form $\times$ irrig & 4386 & 0.576 & 4304 & 0.050 & 4274 & 0.858 \\
\hline
\end{tabular}

Values for each cohort were used as the repeated measures in separate analyses for each of the three dependent variables. Only the effects incorporating cohort are reported here. Significant $(P<0.05)$ effects are shown in bold and non-significant trends $(P<0.10)$ are shown in italics.

no strong patterns are evident in Figs. 2 and 3. Finally, the pattern of the magnitude of density-dependent emergence probability between cohorts also depended on irrigation $(P=0.006$, Table 1$)$.

\subsection{Survival}

Cohort had no impact on survival, with earlier emerging seedlings being no more or less likely to survive to the end of the growing season than later emerging seedlings (Fig. 4; $P=0.434$, Table 1). This is inconsistent with our prediction (ii) of higher survival for early emergents. Also, contrary to our prediction (iii), later cohorts were not consistently more negatively affected by density; instead, almost all significant density dependence was positive (Figs. 5 and 6). The cohort that experienced the most mortality did depend on water supply according to the several significant interactions involving both cohort and irrigation (Table 1), but no clear patterns were evident (Fig. 4). Density-dependent survival varied with cohort and irrigation (Table 1), but again, no consistent patterns in the strength of the density dependence with water supply were apparent (Figs. 5 and 6). 


\section{Desert}

Dicots

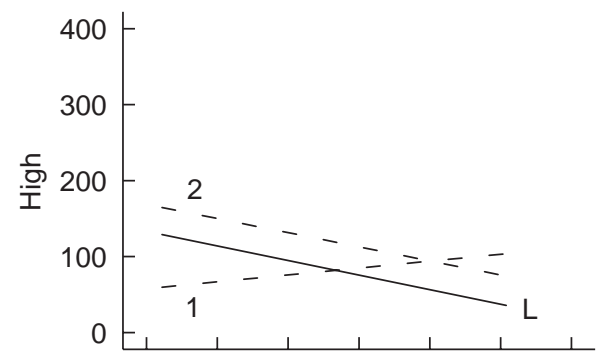

Grasses
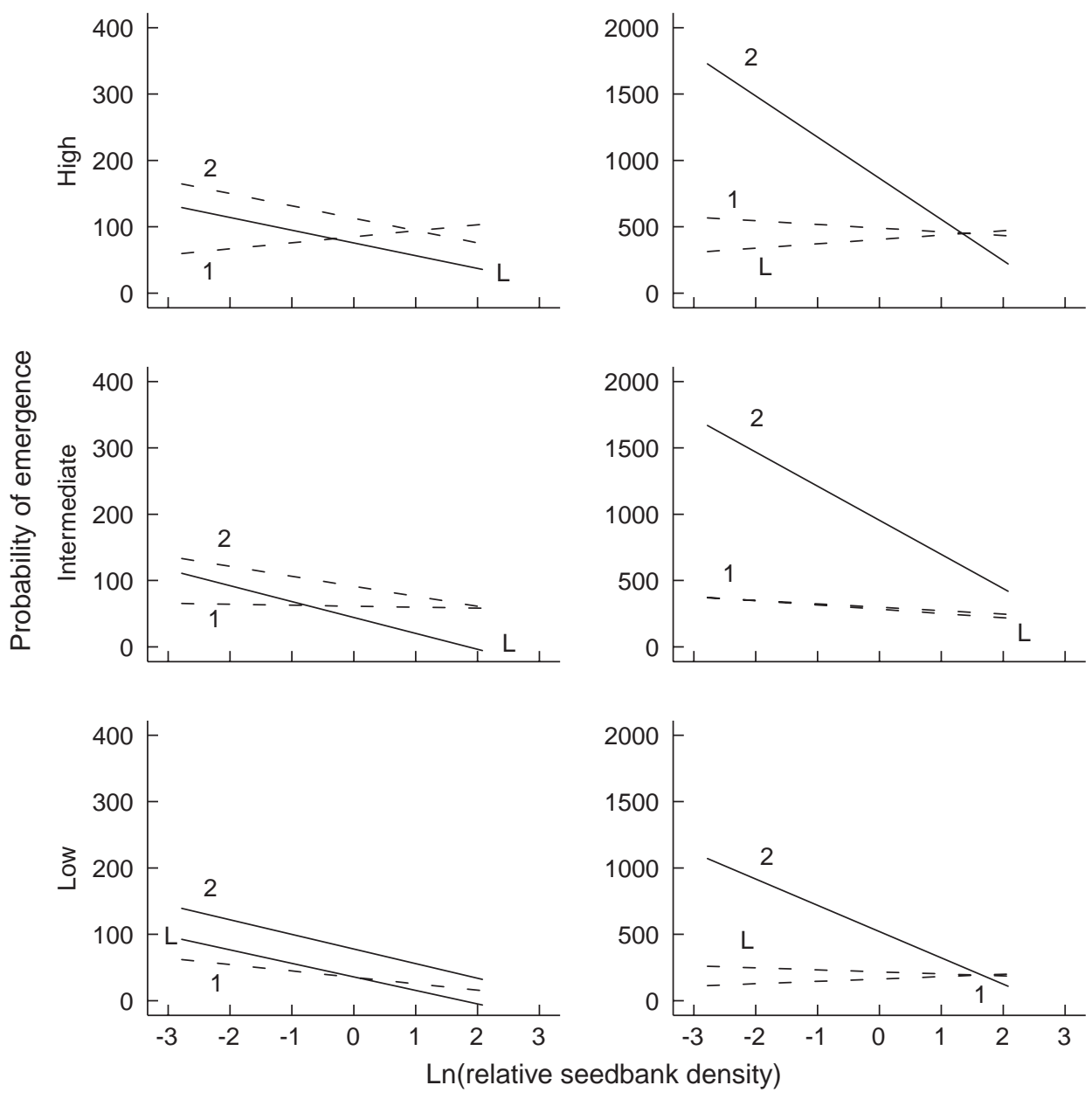

Fig. 2. Probability of emergence (an index calculated as the number of germinants divided by the planting density) of three cohorts for dicots and grasses from the desert source community under three irrigation regimes. Significant regressions are shown as solid lines and non-significant $(P>0.05)$ regressions as dashed lines. Cohorts 1 and 2 are the first two cohorts shown in Fig. 1 and cohort L (late) is the combined cohorts 3-5 shown in Fig. 1. ANCOVAs of these data are shown in Table 1 (interactions involving cohort and density effects).

\subsection{Growth}

Consistent with prediction (ii), earlier emerging seedlings tended to be larger. This was most notable for dicots in the desert site and grasses in the semi-arid site (Fig. 7; reflected in the lack of an overall significant $(P=0.931)$ cohort effect but a significant $(P=0.021)$ cohort $\times$ source $\times$ growth form interaction in Table 1$)$. Such a 
Semi-arid
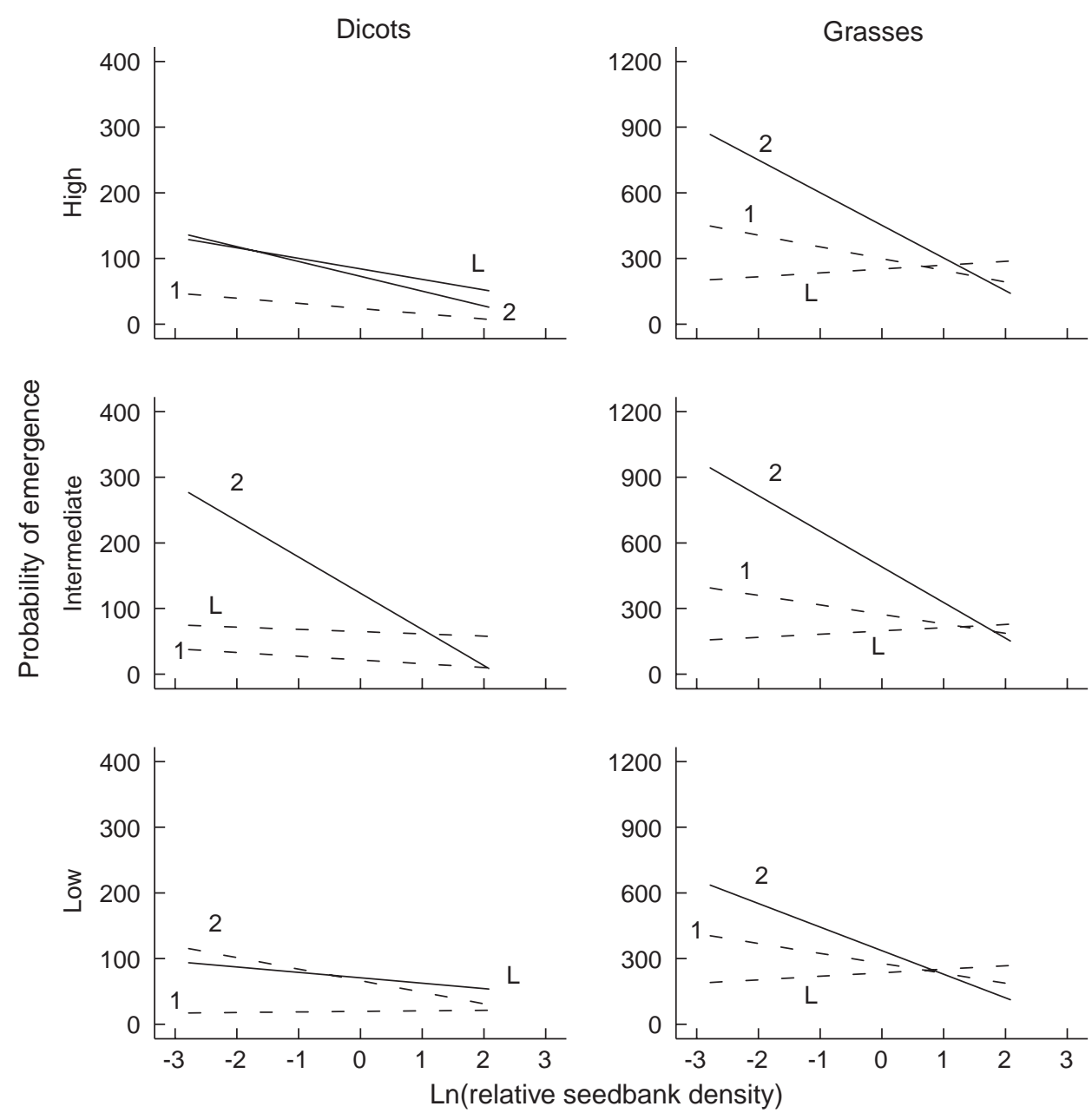

Fig. 3. Probability of emergence (an index calculated as the number of germinants divided by the planting density) of three cohorts for dicots and grasses from the semi-arid source community under three irrigation regimes. Legend as for Fig. 2. ANCOVAs of these data are shown in Table 1 (interactions involving cohort and density effects).

result would be expected based simply on time available for growth, as well as any additional competitive advantages due to resource preemption because of an earlier start to growth. While the effect of both cohort and density-dependence for each cohort did depend significantly on water supply, according to the overall ANCOVA (Table 1), these effects were weak and no consistent patterns in steepness of slopes were apparent in the data (unpublished data). Thus, as we found for survival, in contrast to our predictions, density-dependence of growth was not more negative for later-emerging seedlings. 

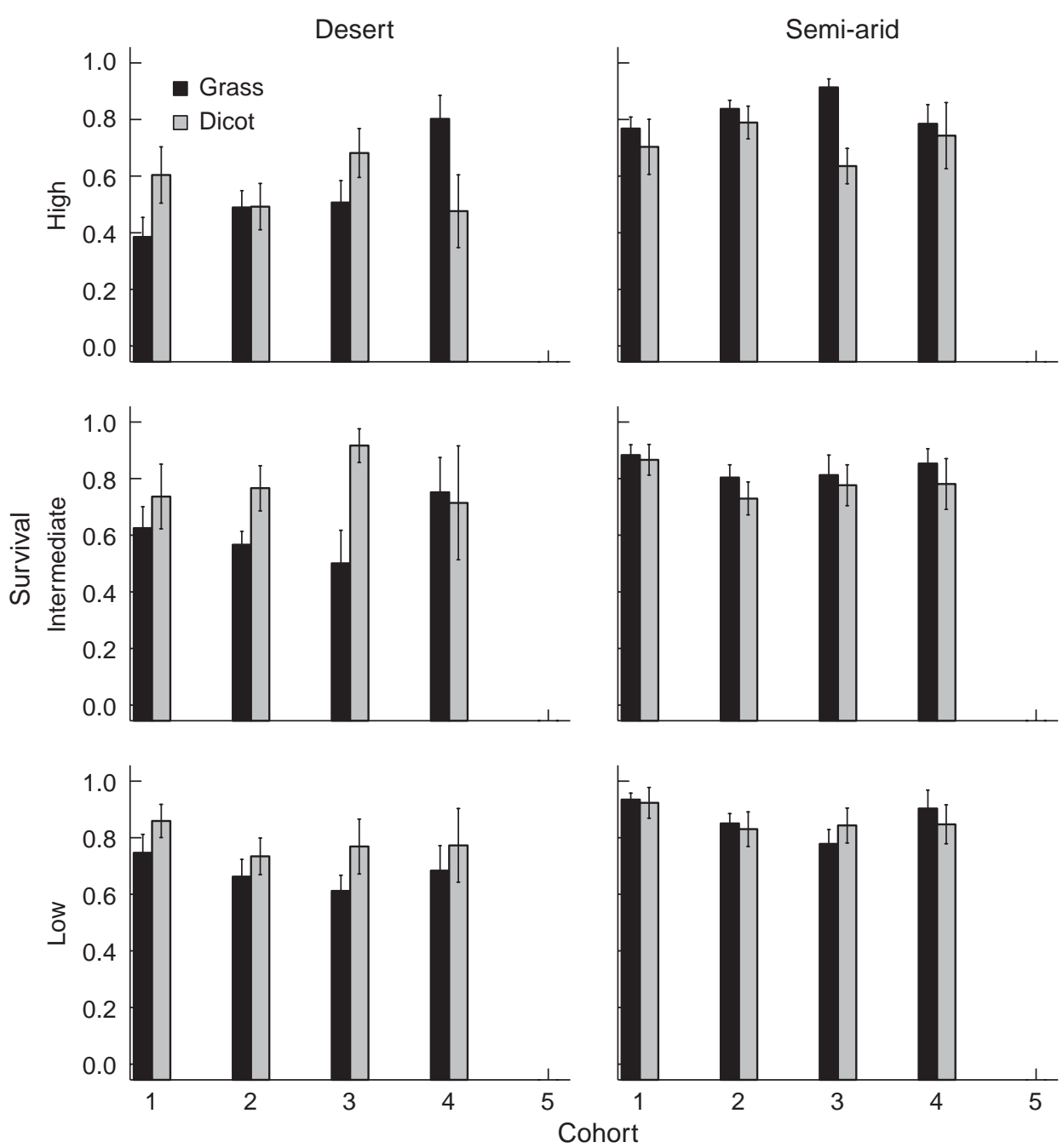

Fig. 4. Effect of timing of emergence (cohort) on survival to the end of the growing season for grasses and dicots from two source communities under three irrigation regimes. Bars are mean $( \pm 1 \mathrm{SE})$ proportion of grass or dicot seedlings surviving from a particular cohort. There are no survival data for cohort 5 because these plants first appeared at the final harvest. ANCOVAs of these data are shown in Table 1 (main effect of cohort and interactions of cohort with source, irrigation, and/or form).

\section{Discussion}

\subsection{Effects of density on emergence timing}

Given the typically strong effects of timing of emergence on density-dependent mortality and growth, it is not unexpected that increasing plant density should 


\section{Desert}
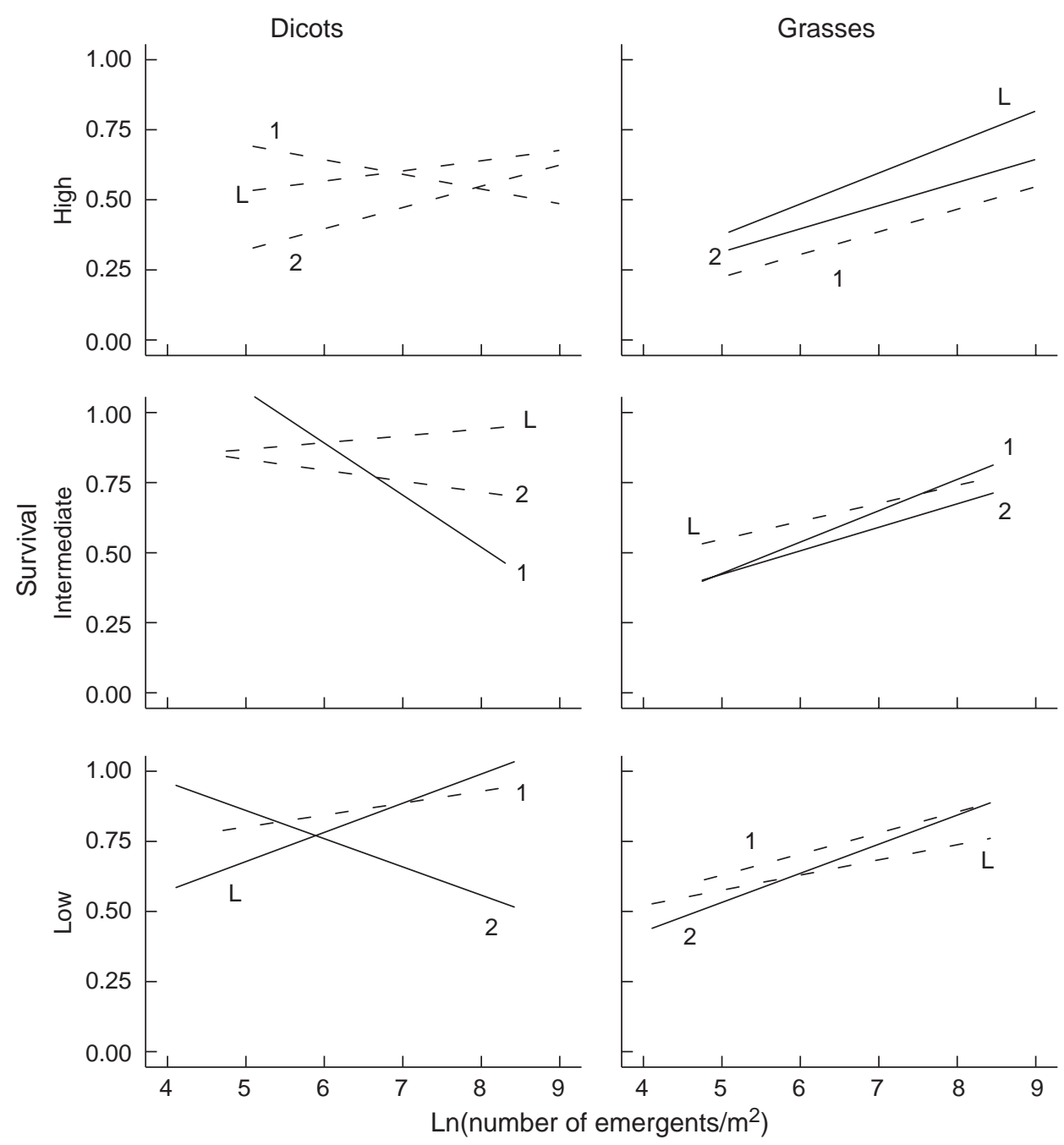

Fig. 5. Density-dependent survival of three cohorts for dicots and grasses from the desert source community under three irrigation regimes. Significant regressions are shown as solid lines and nonsignificant $(P>0.05)$ regressions as dashed lines. Cohorts 1 and 2 are the first two cohorts shown in Fig. 4 and cohort L (late) is the combined cohorts 3 and 4 shown in Fig. 4. ANCOVAs of these data are shown in Table 1 (interactions involving cohort and density effects).

produce directional selection for earlier emergence; such effects have been shown in a number of studies (e.g., Kalisz, 1986; Miller, 1987; Biere, 1991; Stratton, 1992; Miller et al., 1994). However, the question of interest in this study was whether increasing seed, rather than plant, density can elicit a change in timing of emergence. 


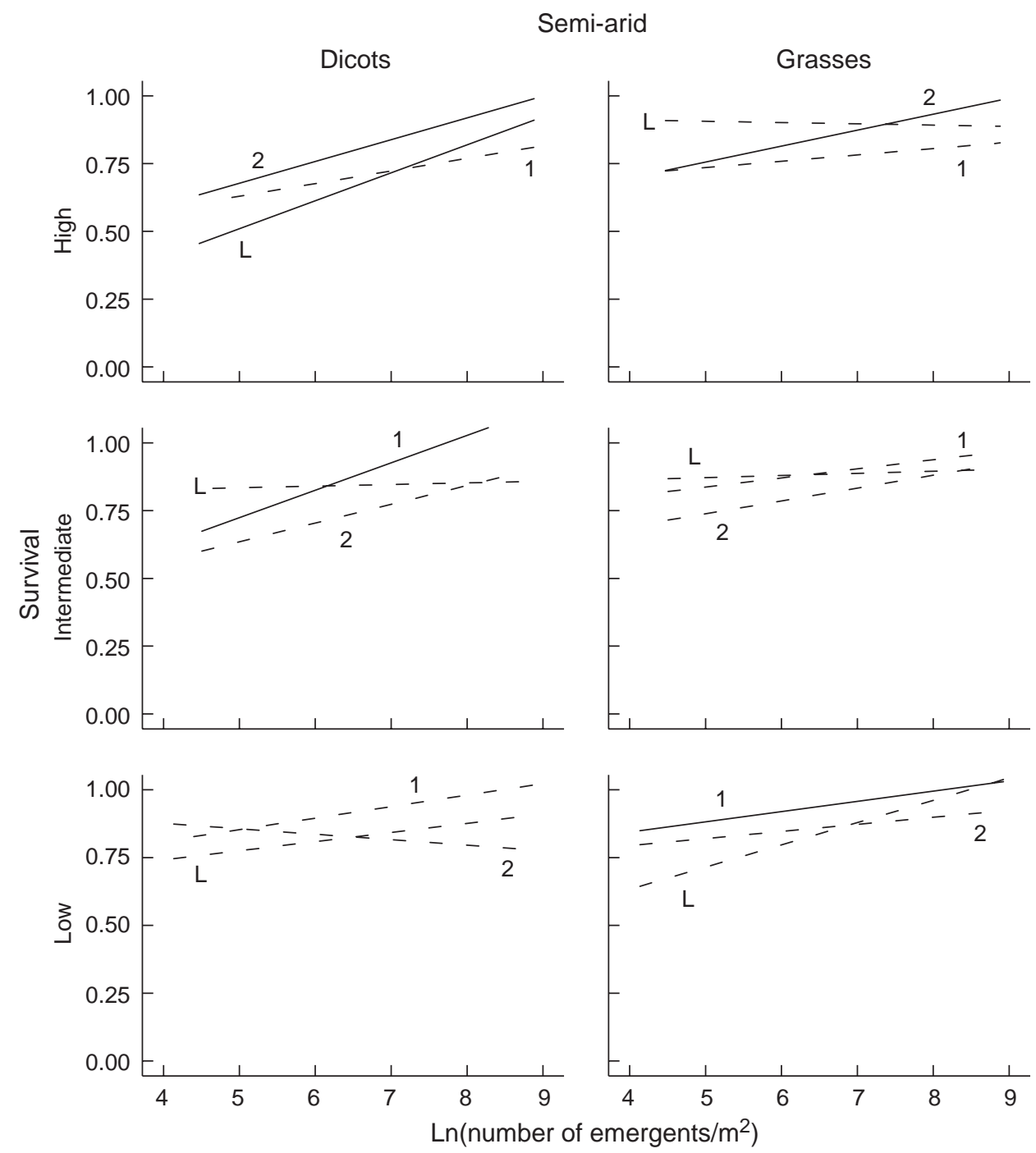

Fig. 6. Density-dependent survival of three cohorts for dicots and grasses from the semi-arid source community under three irrigation regimes. Legend as for Fig. 5. ANCOVAs of these data are shown in Table 1 (interactions involving cohort and density effects).

We found significant evidence for delay of emergence with increasing density for dicots, as indicated by the increasingly negative effects of density for emergence of later cohorts compared to early cohorts. However, grasses did not show any evidence of a shift in timing, with only the largest intermediate cohort showing significant density-dependent emergence. Neither group ever showed positively densitydependent emergence, so that adaptive acceleration is clearly not occurring in this 

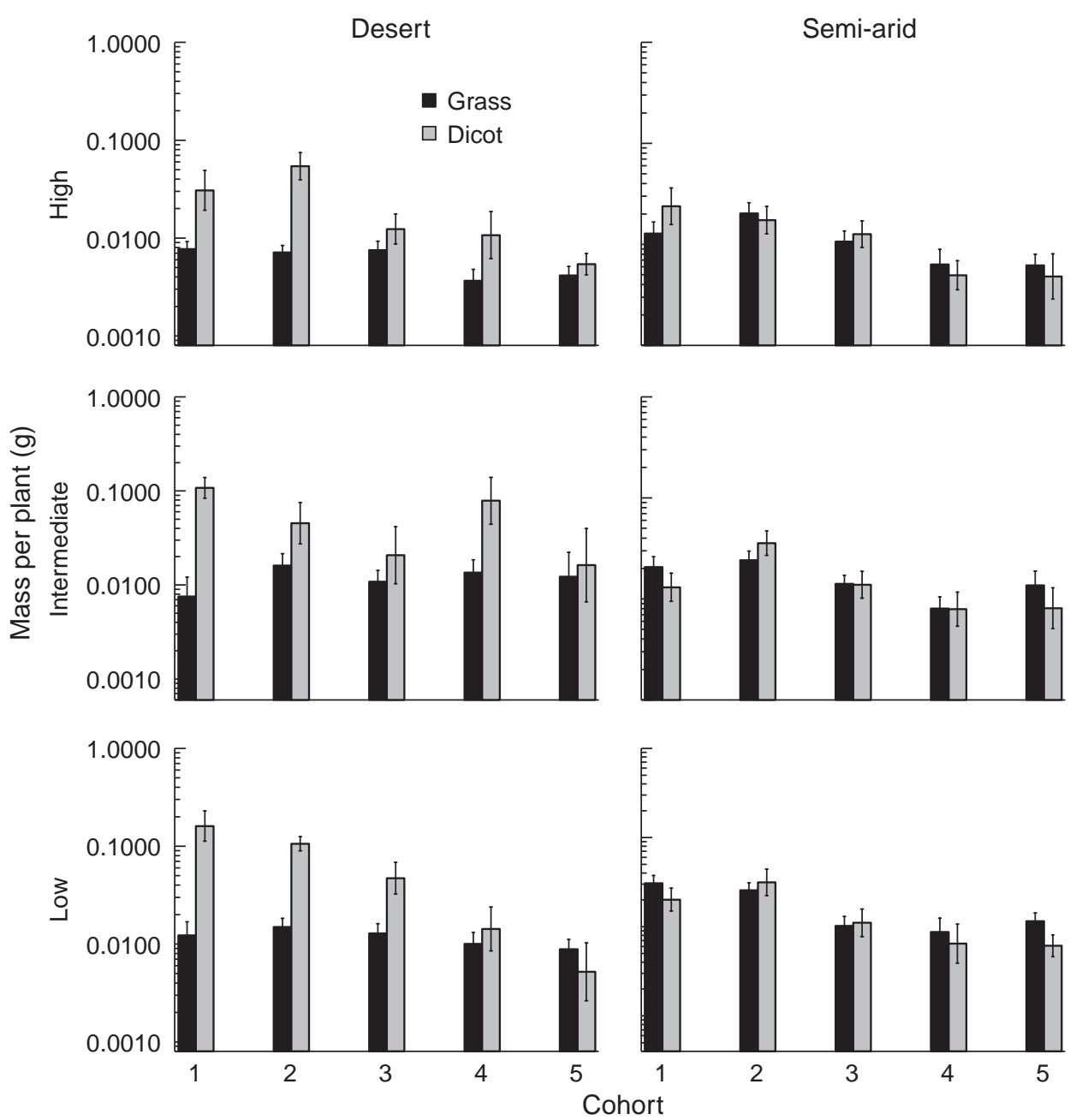

Fig. 7. Effect of timing of emergence (cohort) on plant size at the end of the growing season for grasses and dicots from two source communities under three irrigation regimes. Bars are mean $( \pm 1 \mathrm{SE})$ shoot mass per plant for surviving plants belonging to each cohort. ANCOVAs of these data are shown in Table 1 (main effect of cohort and interactions of cohort with source, irrigation, and/or form).

system. Adaptive acceleration has been described only under controlled experimental conditions and it is not clearly associated with seed density. The ability of seed to detect other seeds suggests a density-dependent basis which would be of particular importance in habitats where emergence timing is critical. However, Bergelson and Perry (1989) compared non-native seeds and Dyer et al. (2000) used non-native seeds around a native perennial and therefore the importance of early emergence may be partially confounded by life history strategy. Seed-seed interactions of this kind remain understudied, though potentially very important to community structure. 
These results are consistent with the relatively poor competitive ability of dicots relative to grasses at the emergence phase, as shown previously in this system (Goldberg et al., 2001). Annual grasses and dicots from semi-arid environments each have non-deep physiological dormancy (Simpson, 1990; Baskin and Baskin, 1998) so differences in dormancy-breaking requirements are probably not a factor, but differential susceptibility to the nature and concentration of surface hormones may play a role. Delayed emergence at higher density may be to a subsequent year ("adaptive delay"), when seeds may experience a more favorable environment, or may simply reflect "competitive inhibition" (Bergelson and Perry, 1989) within that season or to subsequent seasons; our data do not allow us to distinguish between these. Adaptive delay reduces competitive mortality of seedlings but, even for seeds with dormancy, will result in an increased probability of seed mortality before the next season, and a fitness cost due to delayed reproduction even if the seeds survive and germinate in some subsequent year (Bulmer, 1984; Rees, 1997a, b). Competitive inhibition also exposes seedlings to the costs associated with delayed emergence. Adaptive delay requires that seeds be able to sense the density of neighboring seeds or seedlings before "deciding" whether or not to germinate.

\subsection{Mechanisms of density-dependent emergence}

Previous studies, mostly carried out in the laboratory, have shown similar declines in germination and emergence with increasing seed density to those observed in this study, both with increasing density of conspecific seeds (Palmblad, 1968; Linhart, 1976; Waite and Hutchings, 1978, 1979) and, less commonly, of heterospecific seeds (Bergelson and Perry, 1989), as in this study. This density-dependent emergence could be due to either of two general classes of mechanisms: (i) effects of seeds themselves on germination of other seeds and emergence of seedlings or (ii) effects of already-emerged seedlings on subsequent germination, and on the emergence of seedlings.

Our observation that the earliest emerging seedlings were relatively unaffected by the gradient in seed density, while the next cohort to emerge was strongly inhibited by the same gradient, is consistent with inhibition of germination by seedlings rather than seeds, a phenomenon also reported by Juhren et al. (1956); Inouye (1980), and by Bergelson and Perry (1989) who demonstrated that the rate of emergence of three different species was accelerated in the presence of previously sown seeds. However, a mechanism of seedling inhibition, rather than seed inhibition, should also lead to even stronger density-dependence in the later-emerging cohorts, which was not the case, at least for grasses. In addition, if the main mechanism is inhibition by newly emerged seedlings rather than by seeds, the relationship of emergence to density of previously emerged seedlings (surviving from earlier cohorts) should explain more variance than the relationship with seed density. This was not usually the case in this study; $r^{2}$ of regressions of the per-seedling emergence index on density of previously emerged seedlings was actually significantly less than regressions on seed bank density (paired $t$-test, mean difference of $-0.04, n=60, P=0.034$ ). Peltzer, Dyer and Goldberg (unpublished data), using the same source communities as the present 
study, have shown that density-dependent emergence remains even if seedlings are removed within a day after emergence, confirming that it is due to inhibition by seeds rather than seedlings.

Density-dependent effects may also be due to a variety of mechanisms of interaction that have been variously called "non-uptake" (Goldberg 1990, pp. 27-49) or "nontrophic" (Bertness and Callaway, 1994) interactions. In even-aged stands starting from seeds, the seeds or just-emerged seedlings are unlikely to be competing with each other for access to water, nutrient, or light resources. However, it is possible that higher densities of seedlings, especially in the low irrigation, may lead to more rapid drying of the soil that may prevent more germination and increase the risk of death of germinants or larger seedlings. Nevertheless, the mechanism is probably a form of interference competition rather than exploitation competition. Dyer (2004) demonstrated both maternal inhibition (surface hormones) and sibling inhibition (presence of sibling seed) of germination in Aegilops triuncialis. In this study, it is possible that the strength of germination inhibitors on the surface of some grass spikelets weakens with time because on some species the seeds are released from dormancy over time. It is not clear whether such intra-specific inhibition also occurs at the community level and therefore explain our results. Other possible mechanisms include increased local levels of $\mathrm{CO}_{2}$ with increasing seed density (Simpson, 1990), allelochemicals washed from seed coats (Bergelson and Perry, 1989; Murray, 1998) or from litter associated with the seed bank. Inhibition by $\mathrm{CO}_{2}$ from respiration of germinating seeds is unlikely because concentrations are unlikely to be high enough in shallow soil, especially in sand (cf. Baskin and Baskin, 1998).

\subsection{Consequences of emergence timing for survival and growth}

We predicted that, regardless of how and why density affected timing of emergence, earlier emergents would have higher survival and higher growth, and that such advantages of early emergence would be exacerbated at high density due to increased competition. Many studies (e.g., Kalisz, 1986; Miller, 1987; Miller et al., 1994) have shown that earlier emergence results in greater biomass of individual plants, or greater fitness although the outcome is not always consistent (Howell, 1981; Biere, 1991; Stratton, 1992). In contrast, we found that emergence time had relatively little effect on either survival or growth, although there was a tendency for early emerging dicots in the desert and grasses in the semi-arid site to be larger. The general lack of effects of emergence time on subsequent survival and growth in our study system may be because the winter rainfall regime means that, for most of the growing season, temperatures are relatively low and plants remain quite small. Only when temperatures begin to rise during the last 3-4 weeks before the plants and soil dry up at the end of the season do seedlings grow rapidly above-ground. This suggests that there may be little survival or growth advantage to early emergence and that it is only important to be established as a seedling by the onset of the period of rapid growth towards the end of the growing season.

Unlike most studies in more temperate systems, timing of emergence had very little influence on the magnitude of competitive effects on growth or survival. Although 
the importance of timing of emergence on competition has long been a central concept in plant population biology, we speculate that its importance might vary in systematic ways with productivity and with the importance of light as a limiting resource. Small differences in initial size, as such occur with differences in time of emergence, become magnified when competition is size-asymmetric, i.e. when a small size advantage is magnified into a disproportionately large advantage in resource acquisition (Weiner and Thomas, 1986). This has been argued to be much more likely for light, which is supplied unidirectionally, than for soil resources (Weiner and Thomas, 1986). Thus, timing of emergence would be expected to have a larger effect on competition in more productive habitats, such as the temperate fields and woodland understories where most field studies of timing of emergence have taken place (Kalisz, 1986; Miller, 1987; Schmitt et al., 1987; van der Toorn and Pons, 1988; Biere, 1991; Stratton, 1992).

\section{Conclusions}

A final question to consider is why there is such variation in emergence time within a community. Habitat heterogeneity can have a profound influence on the timing of germination. Local-scale variations in the physical environment in factors such as soil topography, depth of seed in the soil, and amount of litter, will provide variation in germination cues for seeds (Kalisz, 1986). In addition, many seeds require scarification, cold-treatments, leaching of germination inhibitors from the seed coat, or other such treatments to induce germination (Baskin and Baskin, 1998). Diversity in germination requirements and a diversity of seed environments will produce a range in the timing of seed germination. We demonstrated that there were no strong fitness consequences of such variation so we may predict that variation in timing of germination will be greater in these arid habitats compared to more temperate regions The question of how this variation in emergence time is maintained has been addressed in more temperate environments (Kalisz, 1986; Biere, 1991; Stratton, 1992) but to date remains untested in arid environments.

\section{Acknowledgements}

We are grateful to the many people who helped in the field, at the sandboxes, in the lab (Achmed Al'Azma, Iris Schmidt, Anat DuMosch, Sergei Volis, Amit Harpaz, Max Taub, Hagit Volin, Larissa Losovsky, Yoram Ayal, Jessica Gurevitch, and members of the Turkington family), or with data analyses (Tim Howard, Wes Hochaska, and Burt Kotler). Financial support was provided by the US-Israel BiNational Science Foundation (BSF 91-00179 to DG and LOW), the National Science Foundation (DEB 96-2973 to DG, RT, and Jessica Gurevitch), a Natural Science and Engineering Research Council of Canada Operating Grant, and a Killam fellowship (to RT) and by the Office of the Vice President for Research at the University of Michigan (to DG). We thank Duane Peltzer for valuable comments on 
an early draft of this paper. This is publication No. 434 of the Mitrani Department of Desert Ecology.

\section{References}

Baskin, C.C., Baskin, J.M., 1998. Seeds: Ecology, Biogeography, and Evolution of Dormancy and Germination. Academic Press, San Diego (666pp).

Bergelson, J., Perry, R., 1989. Interspecific competition between seeds: relative planting date and density affect seedling emergence. Ecology 70, 1639-1644.

Bertness, M.D., Callaway, R.M., 1994. Positive interactions in communities. Trends in Ecology and Evolution 9, 191-193.

Biere, A., 1991. Parental effects in Lychnis flos-cuculi. II. Selection on time of emergence and seedling performance in the field. Journal Evolutionary Biology 3, 467-486.

Bulmer, M.G., 1984. Delayed germination of seeds: Cohen's model revisited. Theoretical Population Biology 26, 367-377.

Clauss, M.J., Venable, D.L., 2000. Seed germination in desert annuals: an empirical test of adaptive bet hedging. American Naturalist 155, 168-186.

Dyer, A.R., 2004. Maternal and sibling factors induce dormancy in dimorphic seed pairs of Aegilops triuncialis. Plant Ecology 172, 211-218.

Dyer, A.R., Fenech, A., Rice, K.J., 2000. Accelerated seedling emergence in interspecific competitive neighborhoods. Ecology Letters 3, 523-529.

Ellner, S., 1986. Germination dimorphisms and parent-offspring conflict in seed germination. Journal of Theoretical Biology 123, 173-185.

Fowler, N.L., 1984. The role of germination date, spatial arrangement, and neighbourhood effects in competitive interactions in Linum. Journal of Ecology 72, 307-318.

Goldberg, D.E., 1990. Components of resource competition in plant communities. In: Grace, J., Tilman, D. (Eds.), Perspectives in Plant Competition. Academic Press, San Diego (484pp).

Goldberg, D.E., Estabrook, G., 1998. A method for comparing diversity and species abundances among samples of different sizes and an experimental example with desert annuals. Journal of Ecology 86, 983-988.

Goldberg, D.E., Turkington, R., Olsvig-Whittaker, L., 1995. Quantifying the community-level effects of competition. Folia Geobotanica and Phytotaxonomica 30, 231-242.

Goldberg, D.E., Turkington, R., Olsvig-Whittaker, L., Dyer, A.R., 2001. Density dependence in an annual plant community: variation among life history stages. Ecological Monographs 71, 423-446.

Harper, J.L., Williams, J.T., Sagar, G.R., 1965. The behaviour of seeds in soil. I. The heterogeneity of soil surfaces and its role in determining the establishment of plants from seed. Journal of Ecology 53, 273-286.

Howell, N., 1981. The effect of seed size and the relative emergence time on fitness in a natural population of Impatiens capensis Meerb. (Balsaminaceae). American Midland Naturalist 105, 312-320.

Hutchings, M.J., 1997. The structure of plant populations. In: Crawley, M.J. (Ed.), Plant Ecology, second ed. Blackwell Scientific Publications, Oxford (717pp).

Inouye, R.S., 1980. Density-dependent germination response by seeds of desert annuals. Oecologia 46, 235-238.

Juhren, M., Went, F.W., Phillips, E., 1956. Ecology of desert plants. IV. Combined field and laboratory work on germination of annuals in the Joshua Tree National Monument, California. Ecology 37, 318-330.

Kalisz, S., 1986. Variable selection on the timing of germination in Collinsia verna (Scrophulariaceae). Evolution 40, 479-491.

Linhart, Y.B., 1976. Density-dependent seed germination strategies in colonizing versus non-colonizing plant species. Journal of Ecology 64, 375-380.

Miller, T.E., 1987. Effects of emergence time on survival and growth in an early old-field plant community. Oecologia 72, 272-278. 
Miller, T.E., Winn, A.A., Schemske, D.E., 1994. The effects of density and spatial distribution on selection for emergence time in Prunella vulgaris (Lamiaceae). American Journal of Botany 81, 1-6.

Murray, B.R., 1998. Density-dependent germination and the role of seed leachate. Australian Journal of Ecology 23, 411-418.

Palmblad, I.G., 1968. Competition in experimental populations of weeds with emphasis on the regulation of population size. Ecology 49, 26-34.

Rees, M., 1994. Delayed germination of seeds: a look at the effects of adult longevity, the timing of reproduction, and population age/stage structure. American Naturalist 144, 43-64.

Rees, M., 1997a. Seed dormancy. In: Crawley, M.J. (Ed.), Plant Ecology, second ed. Blackwell Scientific Publications, Oxford (717pp).

Rees, M., 1997b. Evolutionary ecology of seed dormancy and seed size. In: Silvertown, J., Franco, M., Harper, J.L. (Eds.), Plant Life Histories. Cambridge University Press, Cambridge (313pp).

Rice, K.J., 1987. Evidence for the retention of genetic variation in Erodium seed dormancy by variable rainfall. Oecologia 72, 589-596.

Rice, K.J., Dyer, A.R., 2001. Seed aging, delayed germination and reduced competitive ability in Bromus tectorum. Plant Ecology 155, 237-243.

Ross, M.A., Harper, J.L., 1972. Occupation of biological space during seedling establishment. Journal of Ecology 60, 77-88.

Salisbury, E.J., 1963. Intermittent germination in Capsella. Nature 19, 1303-1304.

Schmitt, J., Eccleston, J., Ehrhardt, D.W., 1987. Dominance and suppression, size-dependent growth and self-thinning in a natural Impatiens capensis population. Journal of Ecology 75, 651-665.

Simpson, G.M., 1990. Seed Dormancy in Grasses. Cambridge University Press, Cambridge, UK (037pp).

Smith, S.E., Riley, E., Tiss, J.L., Fendenheim, D.M., 2000. Geographical variation in predictive seedling emergence in a perennial desert grass. Journal of Ecology 88, 139-149.

SPSS Inc, 1997. SYSTAT for Windows Version 7.01. SPSS, Inc, Chicago, IL, USA.

Stratton, D.A., 1992. Life-cycle components of selection in Erigeron annuus: I. Phenotypic selection. Evolution 46, 92-106.

van der Toorn, J., Pons, T.L., 1988. Establishment of Plantago lanceolata L. and Plantago major L. among grass. II. Shade tolerance of seedlings and selection on time of germination. Oecologia 76, 341-347.

Waite, S., Hutchings, M.J., 1978. The effects of sowing density, salinity and substrate upon the germination of seeds of Plantago coronopus L. New Phytologist 81, 341-348.

Waite, S., Hutchings, M.J., 1979. A comparative study of establishment of Plantago coronopus L. from seeds sown randomly and in clumps. New Phytologist 82, 575-583.

Weiner, J., 1985. Size hierarchies in experimental populations of annual plants. Ecology 66, 743-752.

Weiner, J., Thomas, S.C., 1986. Size variability and competition in plant monocultures. Oikos 47, $211-222$. 